\title{
Nilai-Nilai Moral dan Sosial dalam Penyelenggaraan Kenduri Sudah Tuai di Desa Kumun Mudik Kota Sungai Penuh
}

\author{
Deno Arifianto, Nurman S, Susi Fitria Dewi \\ Program Studi Pendidikan Pancasila dan Kewarganegaraan \\ Universitas Negeri Padang \\ Email : denoarifianto7@gmail.com
}

\section{ABSTRAK}

Penelitian ini dilatar belakangi oleh kenduri Sudah Tuai sudah jarang dilakukan, dimana kenduri Sudah Tuai tidak lagi dilaksanakan rutin setiap tahunnya. Terkadang kenduri dilakukan 2 atau 21/2 tahun sekali. Tujuan penelitian ini Untuk mengetaahui Nilai Moral dan sosial dalam penyelenggaraan Kenduri Sudah Tuai Pada Masyarakat Desa Kumun Mudik, mengidentifikasi peran pemangku adat dalam penyelenggaraan Kenduri Sudah Tuai. Jenis penelitian ini adalah Kualitatif dengan metode Deskriptif. Penetapan informan dilakukan dengan purposive sampling. Jenis data terdiri dari data primer dan sekunder, dikumpulkan melalui observasi, wawancara, dan dokumentasi. Uji keabsahan data menggunakan perpanjangan keikutsertaan, ketekunan pengamatan dan tringulasi. Teknik analisis data melalui reduksi data, penyajian data dan mengambil kesimpulan. Hasil penelitian menunjukan bahwa upacara Kenduri Sudah Tuai yang di laksanakan oleh masyarakat Desa kumun dari dulu sampai sekarang ini bertujuan untuk bersyukur kepada alloh SWT yang telah melimpahkan rahmat dan karunianya kepada masyarakat, baik nikmat umur, dan rezeki. Peran pemangku adat sangat penting dalam acara Kenduri Tuai yang telah senantiasa mengajak anak laki-laki dan perempuan ikut serta berpartisipasi diacara kenduri tersebut. masyarakat kumun mudik sampai saat ini masih mempertahankan tradisi Kenduri Sudah Tuai, di dalam tradisi tersebut terkandung nilai sejarah masa lalu, nilai kebersamaan dan memupuk sikap hormat-menghormati antar warga. Kenduri Sudah Tuai Masyarakat dalam wilayah Depati IV (empat) Batu Gong Tanah Kurnia dapat dilaksanakan setiap tahunnya sebagai kearifan lokal. Selanjut nya tradisi kenduri tuai tetap terjaga dan di wariskan kepada generasi muda.

Kata Kunci: Peran Pemangku Adat, Kenduri

\section{ABSTRACT}

This research is motivated by the kendai Sudah Tuai is rarely done, where the kendai Dawai is no longer carried out routinely every year. Sometimes the feast is done 2 or 21/2 years. The purpose of this study was to find out the moral and social values in the implementation of the Kenduri Tuai In the Community of Kumun Mudik Village, to identify the role of customary stakeholders in the organization of Kenduri Sudah Tuai. This type of research is qualitative with descriptive methods. Determination of informants is done by 
purposive sampling. The type of data consists of primary and secondary data, collected through observation, interviews, and documentation. Test the validity of the data using an extension of participation, perseverance of observation and triangulation. Data analysis techniques through data reduction, data presentation and drawing conclusions. The results showed that the Kenduri Sudah Tuai ceremony which was carried out by the people of Desa kumun from the past to the present aims to give thanks to Allah SWT who has bestowed his mercy and grace on society, both for age, and good fortune. The role of adat holders is very important in the Kenduri Tuai event, which has always invited boys and girls to participate in the festivity ceremony. the slum and hometown community still maintains the Kenduri Dawai tradition, in that tradition it contains the historical value of the past, the value of togetherness and fostering respect among citizens. Kenduri Has Realized Communities in the area of Depati IV (four) Batu Gong Tanah Kurnia can be held every year as local wisdom. Furthermore, the tradition of reviving the harvest is maintained and passed on to the younger generation.

Keywords : role of indigenous stakeholders, Kenduri

\section{PENDAHULUAN}

Adat merupakan perbuatan yang selalu dilakukan sejak dahulu sampai sekarang aturan - aturan itu merupakan kebiasaan yang selalu digunakan dalam masyarakat. Kebiasaan suatu masyarakat yang telah membudaya dalam perbuatan yang dilakukannya itu disebut tradisi. Adapun aturan - aturan yang dilakukan dalam masyarakat tersebut telah menjadi kebiasaan yang selalu dilakukan dalam masyarakat. Kebiasaan-kebiasaan adat itu telah tertuang dalam adat kerinci yang selalu dilakukan masyarakat secara rutin, seperti halnya yang dilakukan oleh masyarakat kumun. Dimana kegiatan adat yang selalu dilakukan oleh masyarakat kumun adalah Kenduri Tuai.

Selain Kenduri Sudah Tuai, juga terdapat beberapa upacara adat yang dipercayai oleh masyarakat kerinci yaitu: kenduri Sko, upacara adat pernikahan, upacara kelahiran anak, upacara cukuran pemberian nama dan kekah, sunat rasul, tradisi adat jambi, serta Kenduri Tuai.

Berdasarkan hasil Observasi awal atau Wawancara awal peneliti dengan bapak Zakirman, salah satu pemangku adat, Menyatakan bahwa Kenduri Tuai adalah kenduri untuk memperingati atau mensyukuri hasil panen yang berlimpah yang dilakukan setelah masyarakat menuai padi atau panen, Dimana kenduri sudah tuai ini dilaksanakan untuk mensyukuri atau berterimakasih kepada Tuhan Yang Maha Esa (YME) dan berterima kasih kepada arwah nenek moyang kita yang telah susah payah mendatarkan yang tinggi dan menimbun yang rendah sehingga terbentuklah sawah.

Kenduri Sudah Tuai ini merupakan salah satu upacara adat yang dapat memelihara hubungan 
silaturahmi, kerjasama, musyawarah, gotong royong terutama masyarakat kumun. mengapa demikian Karena untuk melakukan upacara tersebut masyarakat terlebih dahulu harus melakukan musyawarah. Dimana musyawarah tersebut dilakukan dengan tujuan untuk menentukan biaya dan iuran yang harus dibayar oleh masyarakat kumun perkepala keluarga. Dalam penentuan besarnya iuran tersebut ditetapkan berdasarkan pada jenis pekerjaan masing-masing kepala keluarga. Penentuan besarnya iuran tidak dibagi rata, tetapi berdasarkan kemampuan masingmasing kepala keluarga. Misalnya kepala keluarga yang pekerjaan nya PNS dikenakan iuran lebih besar dibandingkan dengan kepala keluarga yang Non-PNS/petani. Hal ini dilakukan agar masyarakat tidak merasakan terbebani. Dari masalah iuran tersebut terlihat bahwa dari awal akan dilaksanakan kenduri tuia dengan menjunjung nilai dari keadilan dan toleransi.

Selain itu, pelaksanaan Kenduri
Sudah Tuai dapat menjalin sirahturahmi dan membuat hubungan antar masyarakat semakin harmonis, meningkatkan sikap gotong royong dan kerjasama dalam masyarkat kumun. Hal itu dapat terlihat pada saat Kenduri Tuai akan dilaksanakan, dimana masyarakat bersama-sama bergotong royong bekerjasama dalam memasak untuk upacara kenduri tersebut. masing-masing ibu rumah tangga membawa beras 1 gantang, lemang, dan pisang untuk kenduri. Dari hal tersebut bahwa masyarakat saling bahu-membahu dalam upaya mensukseskan kenduri agar dapat terlaksana dengan baik.
Puncak dari kenduri yaitu dimana pada saat hari $H$ kenduri tersebut masyarakat sekampung melakukan makan bersama dan berdo'a sebagai wujud syukur atas nikmat dan karunia yang diberikan oleh alloh SWT. Tidak hanya itu, setelah acara makan bersama selesai semua tamu undangan yang hadir pada hari itu juga diberikan lemang dan pisang yang telah dikumpulkan dalam kenduri tersebut. Yang paling Khas nya lagi, yaitu dalam acara kenduri tersebut terdapat lemang yang dibuat khusus, masyarakat menamakannya Lemang Kaeh (lemang yang diikat setiap per 3 batang) dan pisang 1 sisir dalam setiap lemang kaeh tersebut. Dimana lemang tersebut khususnya diberikan kepada ninik mamak/orang adat. Mengapa demikian? Karena, masyarakat memberi penghormatan dan ucapan terima kasih kepada orang adat yang telah mengarahkan anak jantan dan anak betino untuk turun kesawah.

Kenduri Sudah Tuai ini dilakukan oleh masyarakat kerinci karena pada dasarnya suku kerinci tersebut mendiami daerah yang tergolong subur dimana daerahnya dikelilingi oleh bukit-bukit, dan didaerah ini pula terdapat gunung yang tertinggi disumatra yaitu Gunung Kerinci. Sehingga sebagian besar masyarakatnya adalah petani, dan terkenal dengan petani yang ulet dan rajin. Serta sawah-sawah yang ada di kerinci sangat baik sistem perairannya dengan memanfaatkan air yang ada di gunung. Dengan kondisi alam yang demikian menyebabkan di daerah kerinci tersebut banyak upacara-upacara tradisional yang dilakukan terutama yang berhubungan dengan kesuburan 
tanah. Salah satunya yang telah disebutkan di atas yaitu upacara/ Kenduri Tuai.

Berdasarkan hasil observasi dan wawancara peneliti dengan Bapak Zakirman, upacara/ Kenduri Sudah Tuai tersebut sudah jarang dilakukan. Dimana Kenduri Sudah Tuai tidak lagi dilaksanakan rutin setiap tahunnya. Terkadang kenduri dilakukan 2 atau 21/2 tahun sekali. Pemangku adat dalam menentukan pelaksanaan Kenduri Sudah Tuai tidak lagi sesuai dengan peraturan yang sudah ada sejak dulu, sehingga pelaksnaan Kenduri Sudah Tuai tersebut tidak sesuia dengan peraturan yang sudah ada.

Selain itu, partisipasi masyarakat dalam Kenduri Sudah Tuai juga sudah menurun dimana yang biasanya masyarakat kumun melakukan kegiatan melemang dan menanak nasi dilakukan oleh seluruh masyarakat baik yang memiliki sawah maupun yang tidak memiliki sawah. Penurunan partisipasi ini ditandai dengan: tidak seluruhnya masyarakat berperan aktif dalam menyelenggarakan upacara seperti halnya masyarakat yang tidak bermata pencaharian sebagai petani/ masyarakat yang tidak memiliki sawah tidak lagi ikut serta dalam membayar iuran, melemang dan menanak nasi untuk Kenduri Tuai tersebut.

Para pemuda-pemudi dan anak-anak sudah tidak aktif lagi mengikuti upacara/ Kenduri Sudah Tuai tersebut, bisa dikatakan Kenduri Sudah Tuai sekarang hanya dihadiri oleh orang-orang tua saja. Disamping itu juga berkurangnya peran depati nenek mamak dalam memberikan arahan demi terselenggaranya Kenduri Sudah Tuai dalam masyarakat.

Selanjut nya masalah yang timbul dalam pemangku adat yaitu tidak semua pemangku adat dapat menghadiri acara kenduri sudah tuai hal ini di sebabkan oleh berbagai halangan yang di hadapi oleh pemangku adat. Disamping terbatas nya pemangku adat yang tersedia karena jabatan pemangku adat di pegang oleh seseorang sampai ia meninggal, dan setelah itu dapat diganti dengan yang baru. Hal ini di benarkan oleh bapak Zakirman salah satu pemangku adat.

\section{METODE PENELITIAN}

Jenis penelitian ini adalah metode penelitian kualitatif Menurut Bogdan dan Taylor dalam Moleong (2005) metodologi kualitatif sebagai prosedur penelitian yang menghasilkan data deskriptif berupa kata-kata tertulis atau lisan dari orang-orang dan perilaku yang dapat diamati. Metode deskriptif menurut Moleong (2005) metode dalam mengumpulkan data dengan kata-kata, gambar, dan bukan angka-angka.

Lokasi penelitian adalah Desa Kumun Mudik, Kecamatan Kumun Debai, kota sungai penuh. Kerinci. Informan penelitian diambil secara purposive. Menurut Moleong (2005) purposive sampling merupakan teknik penentuan sampel dengan pertimbangan khusus sehingga layak dijadikan sampel, orang yang benarbenar mengetahui dengan jelas permasalahan yang diteliti.

Sesuai dengan tujuan yang hendak dicapai, maka sumber data 
diperoleh dari data primer dan data sekunder. Pengumpulan data dilakukan dengan teknik observasi, wawancar, dokumentasi. Analisis data dalam penelitian kualitatif dilakukan pada saat pengumpulan data berlangsung dan setelah selesai pengumpulan data dalam periode tertentu. Pada saat wawancara, peneliti sudah melakukan analisis terasa belum memuaskan, maka peneliti akan melanjutkan pertanyaan sampai tahap tertentu sehingga diperoleh data yang kredibel. Dengan demikian aktifitas dalam analisis data kualitatif dilakukan secara terusmenerus sampai tuntas sehingga datanya jenuh, Miles dan Huberman dalam Sugiyono (2012:246).

\section{HASIL DAN PEMBAHASAN}

\section{Nilai Moral dan Sosial Dalam Penyelenggaraan Kenduri Sudah Tuai pada Masyarakat Desa Kumun Mudik}

a. Nilai religius atau percaya kepada Tuhan yang Maha Esa.

Masyarakat Kumun Mudik adalah masyarakat mayoritas pemeluk agama islam, Di dalam agama di anjurkan untuk banyak bersyukur. Kenduri Sudah Tuai merupakan perwujutan masyarakat bersyukur kepada alloh SWT, sebagai ucapan syukur apa yang telah di berikan Alloh rezeki terutama setelah melaksanakan panen di sawah. Kenduri Sudah Tuai merupakan upacara adat pada dasarnya kebiasaan masyarakat yang bersumber dari alloh SWT, seperti disampaikan oleh $\mathrm{H}$. Amirudin hasil wawancara pada tanggal 28 maret 2019. Dalam petitih adat nya:

" Manaolah adat lamao, adat bersandi syarak bersendikan kitabulloh, adat kumun pusako usang, ngan idak lapaok di hujan, idak lekang di paneh syarak ngatao adat make".

"Dimana adat dahulu, adat berdasarkan syarak/hukum, dan syarak bersandikan kitab alloh, adat dahulu pusaka lama tidak hancur kena hujan atau panas, hukum tertulis adat yang prakteknya.

Dari hasil wawancara di atas tradisi kenduri tuai bukan menyimpang dari ketentuan Allah, melainkan perwujudan ajaran agama yang diterapkan masyarakat dalam kehidupan sehari-hari sebagai bentuk ketaatan masyarakat terhadap sang penciptanya.

b. Nilai Kekeluargaan dan Kebersaamaan

$$
\text { Keluarga adalah bentuk }
$$

hubungan manusia yang terjalin karena adanya sebuah ikatan, baik karena ikatan perkawinan maupun persaudaraan. Dengan adanya kenduri tuai makin memperkuat hubungan kekeluargaan maupun persaudaraan antar masyarakat desa kumun mudik, hal ini terlihat dalam persiapan cara kenduri tuai tidak hanya dirasakan oleh masyarakat berprofesi petani, tetapi masyarakat yang lain pegawai negeri, wira swasta, dll. Ikut berpartisipasi dalam memeriahkan kenduri tuai, begitu juga dalam acara pelaksanaan semua masyarakat tanpa memandang latar belakang status sosial semua diperlakukan sama. seperti terlihat dalam gambar persiapan yang dilaksanakan masyarakat dalam acara kenduri tuai.

Kenduri Sudah Tuai yang di laksanakan oleh masyarakat Kumun Mudik dapat memupuk rasa kebersamaan yang terealisasi dalam bentuk tolong-menolong dan gotong royong. Hal ini seperti di ungkapkan 
dalam petitih adat di Kemukakan oleh H. Amirudin Depati pada tanggal 28 maret 2019.

“ Manao lah tumbuh nyo gawe sno ineh de break samo-samo kitao miku, de inga ndo samo-saaamo kitao nyinjek, manao nga jaeuh intok tulao kayao ngimbo, manao nga dakaek intok yulao kayao ngambiek"

" Bagaimana saat nya kerja seperti ini, kalau berat sama-sama kita pikul, kalau lah ringan sama-sama kita jinjing, dimana orang/ keluarga yang minta tolong di seru dan mana keluarga yang dekat minta tolong di panggil".

Acara Kenduri Sudah Tuai yang di laksanakan Desa Kumun Mudik yang setiap tahun pada saat setelah panen padi di sawah, dengan sendirinya dapat mempertahankan sifat kebersamaan, gotong royong yang selalu hidup di tengah masyarakat, dimana pekerjaan berat sama-sama di pikul begitu yang ringan sama-sama di jinjing dan seluruh warga dikumpul menjadi satu untuk memeriahkan acara tersebut.

Kenduri Sudah Tuai merupakan tradisi masyarakat Kumun pada umumnya dan masyarakat Desa Kumun Mudik khusus nya yang sudah dilaksanakan sejak dulu dari zaman nenek moyang sampai saat ini secara turun temurun, yang keberadaan nya tidak dapat di pastikan secara tertulis, karena Kenduri Sudah Tuai merupakan kebiasaan yang hidup dalam masyarakat yang sifat nya turun temurun, hal ini di kemukakan oleh salah satu tokoh adat di Kumun yakni dalam petitih adat nya: dikemukakan oleh H. Amirudin Depati pada tanggal 28 maret 2019.

" Ramao-ramao si kumbak jantie, hkatib indah bailk bakudeo, patah tumbaoh hila baganti adat lamao sno itoh ugeo"

“Kupu-kupu dan kumbang yang kaki putih khatib/buya tidak pulang berkuda.patah tumbuh hilang berganti, adat lama dan sekrang begitu juga".

Dari petitih adat di atas bahwa tradisi dari dulu sampai sekarang sama saja, termasuk juga Kenduri Sudah Tuai dari dulu sudah bergantiganti generasi sampai saat ini masih di pertahankan.

c. Memelihara Sikap saling Menghormati

Tradisi Kenduri Sudah Tuai yang tetap di pertahankan oleh masyarakat Kumun Mudik dapat juga memelihara sikap saling menghormati antara warga masyarakat, tokoh masyarakat,tokoh adat, lembaga pemerintah dan masyarakat umum nya, dimana semuanya di tempatkan sesuai peran nya masing-masing juga termasuk tamu undangan. Seperti ditemukan dalam petitih adat oleh Dahrun mangku salah satu ninek mamak Desa Kumun Mudik yaitu :

“ Tibo kamai lah kayao sambauk, datea kamai lah kayao tantaek, lah kayao duduk pado tampek nga sapatuk nyo, lah dikatengahkan pulao nasi nga suak, gule ngan satangkae, ayae ngan sagiuk kayao persembahkan menghormati kamai"

"Kedatangan kami di sambut, kedatangan kami sudah di tunggu, di persilahkan duduk menurut sepatut nya. Di ketengahkan berupa jamuan, nasi lauk pauk dan serta minuman untuk menghormati masyarakat yang datang

"Jadi dapat di simpulkan masyarakat Desa Kumun Mudik sangat menghormati tokoh tokoh masyarakat yang sangat berperan 
terhadap kemajuan masyarakat Kumun Mudik di segala bidang begitu juga tokoh adat yang selalu memperhatikan anak kemenakan nya juga masyarakat agar dapat hidup aman, rukun selalu menjalankan aktifitas kehidupan nya.

Dari uraian tersebut di atas dapat di simpulkan bahwa Nilai-nilai moral dan sosial terkandung dalam acara kenduri tuai yakni, nilai kebersamaan, kegotongroyongan, nilai keagamaan, nilai kerja sama, dalam tradisi tersebut terkandung nilai sejarah masa lalu, nilai kebersamaan dan memupuk sikap hormatmenghormati antar warga. Kenduri yang dilksanakan oleh masyarakat merupakan contoh rasa kebersamaan gotong royong yang selalu dilestarikan oleh masyarakat dan membentuk rasa persatuan dan kesatuan. Selanjut nya tradisi kenduri tuai tetap terjaga dan di wariskan kepada generasi muda sebagai bukti bahwa masyarakat Kumun Mudik memiliki tradisi yang sifat nya turun temurun walaupun di tengah kemajuan zaman, namun masyarakat tidak melupakan tradisi nenek leluhur yang di wariskan

2. Peran Pemangku Adat dalam Kenduri Tuai

Peran Pemangku Adat didalam Kenduri Sudah Tuai adalah Mengajun arah anak jantan anak butino di RT yang melaksanakan kenduri tuai. Memberi kesadaran pada masyarakat bahwa kenduri Sudah Tuai penting dilaksanakan sebagai ucapan syukur.

Menurut Bapak H. Amiruddin Dpt menyatakan bahwa Para pemangku adat senantiasa mengajak anak jantan anak butino mempelajari memahami mengamalkan adat lama pusako usang, adat yang bersandi syarak, syarak bersandi kitabulloh, Syarak mengatakan adat memakainya. Para pemangku adat. Depati nenek mamak selalu menukikkan pandang dekat, melayangkan pandang jauh, dekat berpagar mato, jauh berpagar hati, anto dekat dikadano, anto jauh diulangi. Mamak berbudi baik, keponakan berbaso elok, sehingga terjalin hubungan yang harmonis.

Peran pemangku adat sangat penting yang terdiri dari Depati, nenek mamak, dan tengganai diantaranya adalah:

a. Melaksanakan musyawarah yang diusulkan oleh kelompok masyarakat yang akan melaksanakan kenduri tersebut, dalam musyawarah diputuskan hal-hal seperti jumlah keluarga yang ikut dalam kenduri tuai kemudian menetapkan hari dan tanggal pelaksanaan, mengumpulkan data jumlah undangan yang menghadiri acara kenduri Sudah Tuai. b. menyampaikan hajatan atau maksud dari acara tersebut.

Peran pemangku adat ialah Mengarahkan tahap-tahap yang harus dilalui dalam pelaksanaan kenduri Sudah Tuai agar kenduri tersebut berjalan dengan lancar serta mengimbau semua unsur masyarakat untuk sama-sama terlibat dalam kegiatan kenduri Sudah Tuai yaitu semua anggota keluarga untuk samasama mengantarkan nasi dan lemang ditempat yang telah di tentukan.

Jadi, dapat disimpulkan bahwa peran pemangku adat adalah tokohtokoh adat senantiasa mengajak anak jantan anak butino mempelajari memahami mengamalkan adat lama serta Mengajun arah anak jantan anak butino di RT yang melaksanakan kenduri Sudah Tuai. Memberi kesadaran pada masyarakat bahwa 
kenduri Sudah Tuai penting dilaksanakan sebagai ucapan syukur kepada Alloh SWT. Mengimbau masyarkat untuk sama-sama melaksanakan kegiatan kenduri tuai dan juga mengharapkan terjadinya sifat kerja sama dan gotong royong dalam kehidupan masyarakat.

\section{KESIMPULAN}

Berdasarkan temuan peneliti yang penulis lakukan di desa Kumun Mudik, Kota Sungai Penuh, tentang peran pemangku adat dalam penyelenggaraan Kenduri Sudah Tuai di desa Kumun Mudik, Kota Sungai Penuh dapat disimpulkan bahwa pelaksanaan Kenduri Sudah Tuai pada masyarakat desa Kumun Mudik bertujuan untuk mengucapkan rasa syukur kepada yang maha kuasa yang telah memberikan hasil panen yang berlimpah dan hasil ladang yang juga memuaskan serta Kenduri yang dilksanakan oleh masyarakat merupakan contoh rasa kebersamaan gotong royong dan membentuk rasa kesatuan dan persatuan. Tradisi ini diyakini oleh masyarakat desa Kumun Mudik sebagai salah satu lambang kesatuan dan persatuan serta sifat gotong royong dalam masyarakat.

Peran pemangku adat dalam Kenduri Sudah Tuai yaitu senantiasa mengajak anak jantan anak butino mempelajari memahami mengamalkan adat lama serta Mengajun arah anak jantan anak butino, Memberi kesadaran pada masyarakat bahwa kenduri tuai penting dilaksanakan.

\section{DAFTAR PUSTAKA}

Ahmadi. (2009). Ilmu Sosial Dasar; jakarta: Rineka Cipta.

Amiruddin. (2013). Istilah Kata - kata Adat. Kumun.

Iskandar. 2008. Metodologi Penelitian

Pendidikan dan sosial (kuantitatif dan Kualitatif). Jakarta : Gaung Persada Press.

Lexy J. Moleong. 2013. Metodologi Penelitian Kualitatif Edisi Revisi. Bandung: Remaja Rosdakarya.

Sugiyono. 2012. Metode Penelitian Kuantitatif Kualitatif. Bandung : Alfa Beta. 